\title{
As Técnicas de Relatos Orais e - Estudo das Representações Sociais em Saúde
}

\author{
Raquel Maria Rigotto ${ }^{1}$
}

\begin{abstract}
Resumo: O artigo apresenta uma revisão bibliográfica sobre as técnicas de Relatos Orais, largamente utilizadas hoje como alternativa metodológica em estudos qualitativos, que partem da experiência de vida dos indivíduos para desvelar as relações sociais e a cultura nas quais se insere. Reúne seu histórico e define as técnicas de História Oral, História de Vida, Depoimento Pessoal, Autobiografia e Biografia, apresentando suas diferenças e aplicações específicas. Discute seus pressupostos, como a ruptura com os mitos da objetividade do real e da neutralidade do investigador; o entendimento do ser humano como produto e, ao mesmo tempo, produtor da sociedade, situado na tensão sujeito-estrutura, indivíduo-sociedade. Em seguida, avalia a adequação destas técnicas para o estudo das representações sociais em saúde, tomando um exemplo no campo das relações entre saúde e trabalho. Finalmente, destaca algumas orientações práticas para o pesquisador na aplicação destas técnicas.
\end{abstract}

Palavras-chave: Relatos Orais; Representações Sociais; Saúde e Trabalho.

Summary: The paper presents a bibliographical review about Oral Reports techniques, currently largely employed as a methodological alternative in qualitative studies which issue out of life experiences of individuals to unfold the social relationships and culture to which they belong. The work collects the background of Oral Reports and the techniques of Oral History, Life History, Personal Testimony, Autobiography and Biography, presenting their differences and specific applications. It debates its presuppositions such as the breaking away with the myths of objectivity of the real and the neutrality of the researcher; the understanding of the human being as a product and at the same time as a producer of society, positioned on the subject-structure, individual-society tension. Next, it appraises the adequacy of these techniques for the study of social representations within health, taking an example in the field of the relationships between health and work. Finally, it highlights some practical guidelines for the benefit of the researcher in the application of these techniques.

Keywords: Oral Reports; Social Representations; Health and Work.

'Departamento de Saúde Comunitária. Universidade Federal do Ceará, Fortaleza. 


\section{Introdução}

O propósito deste trabalho é percorrer a bibliografia sobre as técnicas de Relatos Orais, amplamente utilizadas atualmente em estudos qualitativos, identificando seu histórico e conceitos. Apresenta e discute seus pressupostos teórico-metodológicos. Pretende também discutir sua adequação como alternativa metodológica para o estudo de representações sociais sobre saúde, tomando um exemplo aplicativo no campo das relações entre saúde e trabalho. Finalmente, destaca algumas orientações práticas para o pesquisador na aplicação destas técnicas.

\section{I - Histórico}

Ao reconstruir a história dos Relatos Orais, Maria Isaura Pereira de Queiroz parte de um ponto muito interessante: o papel que eles desempenham, através dos séculos, na transmissão e conservação do conhecimento e, portanto, como fonte de dados para as ciências em geral. "O relato oral está na base da obtenção de toda sorte de informações $e$ antecede a outras técnicas de obtenção $e$ conservação do saber; a palavra parece ter sido senão a primeira, pelo menos uma das mais antigas técnicas utilizadas para tal. Desenbo e escrita lhe sucederam" (Pereira de Queiroz, 1988:16).

Sua utilização enquanto técnica de coleta de material por cientistas sociais remonta ao final do século XIX, com os estudos antropológicos, como o de Franz Boas, recuperando a memória tribal de índios americanos. No início do século XX registram-se os trabalhos sociológicos de John Dollard (1900), N.I. Thomas e F. Znaniecki (1918-1920).

Entretanto, Ethel Kosminsky, citando Roger Bastide, situa a origem da técnica de histórias de vida na Psicologia, mencionando a pesquisa de Allport, Bruner e Jandorf, datada de 1941, sobre a revolução nazista - o que traria algumas implicações no desenvolvimento da técnica (Kosminsky, 1986:31). Merece ainda destaque o trabalho de Oscar Lewis, intitulado Os Filhos de Sanchez, que, além de introduzir o uso do gravador, contribuiu com a transição da utilização da técnica do campo da Psicologia para o da Antropologia sócio-cultural.

Nos anos seguintes, entretanto, os relatos orais e as histórias de vida foram relegados a segundo plano. Olga von Simon atribui este fato à tentativa, levada a cabo pelas Ciências Sociais, de aproximar-se do status das ciências exatas. Num contexto de valorização das técnicas quantitativas, eram os quadros, as tabelas, os gráficos que davam validade científica à pesquisa sociológica, fornecendo-lhe dados inquestionavelmente objetivos e eliminando deles a influência da psique individual, introduzida pelas histórias de vida.

Queiroz descreve com acuidade o passo seguinte:

"Pouco a pouco se percebeu, no entanto, que valores e emoção permaneciam escondidos nos próprios dados estatísticos, já que as definições das finalidades da Pesquisa e a formulação das perguntas estavam profundamente ligadas à maneira de pensar e de sentir do pesquisador, o qual transpunba assim para os dados, de maneira perigosa porque invisivel, sua própria percepção e seus preconceitos. Os números perdiam sua auréola de pura objetividade, patenteando-se dotados de vieses anteriores ao momento da coleta, escondidos na formulação do problema $e$ do questionário; ocultos, pareciam inexistentes... Porém, influenciavam o levantamento, desviando-o muitas vezes do rumo que deveria seguir" (Pereira de Queiroz, 1988:15).

No Brasil, a técnica das histórias de vida e dos relatos orais tem um breve aparecimento nos anos 40 e início dos anos 50, com os trabalhos de Roger Bastide, Renato Jardim 
Moreira, Maria Isaura Pereira de Queiroz e Florestan Fernandes. Passa em seguida por período de eclipse, justificado também aqui pelo encantamento com as técnicas estatísticas e pelo entendimento da subjetividade como fator de desvio e erro na interpretação do real.

Seu ressurgimento, a partir dos anos 70 , é marcado na área de psicologia social, em estudo conduzido por Ecléa Bosi, sobre a memória enquanto atributo humano estreitamente dependente da vida social e por ela determinada.

Recentemente, em nosso país, a técnica foi estendida à investigação na área propriamente sociológica, onde se busca "o esclarecimento de relações coletivas entre individuos num grupo, numa camada social, num contexto profissional, noutras épocas e também agora" (Pereira de Queiroz, 1988:24). Entre os estudos representativos deste momento, situam-se o de Eva Alterman Blay, intitulado Os Judeus na Memória de São Paulo; os desenvolvidos pelo Centro de Pesquisa e Documentação de História Contemporânea do Brasil - CPDOC e os ligados ao Centro de Estudos Rurais e Urbanos - CERU. O Relato Oral e a História de Vida renascem vigorosos, especialmente num contexto de avanço em relação às técnicas quantitativas e à abordagem da subjetividade.

\section{II - Conceitos e Definições}

A bibliografia consultada apresenta uma série de denominações - Relato Oral, História Oral, História de Vida, Depoimento Pessoal etc. - nem sempre bem definidas, e às vezes com conceitos pouco homogêneos entre os diversos autores. Verena Alberti expressa essa dificuldade, atribuindo-a ao fato de que os limites desta técnica estariam em "categorias de diversas disciplinas das ciências bumanas. (...) Sua especificidade está no próprio fato de se prestar a diversas abordagens, de se mover num terreno pluridisciplinar"
(Alberti, 1989:1). Tentaremos sistematizar a seguir alguns destes conceitos.

\section{1 - História Oral}

"É um método de pesquisa (bistórica, antropológica, sociológica, etc.) que privilegia a realização de entrevistas com pessoas que participam de, ou testemunharam, acontecimentos, conjunturas, visões de mundo, como forma de se aproximar do objeto de estudo. Trata-se de procurar compreender a sociedade através do individuo que nela viveu; de estabelecer relações entre o geral e o particular através da análise comparativa de diferentes versões e testemunhos" (Alberti, 1989:1-3).

"É termo amplo que recobre uma quantidade de relatos a respeito de fatos não registrados por outro tipo de documentação, ou cuja documentação se quer completar. Colbida por meio de entrevistas de variadas formas, ela registra a experiência de um só individuo ou de diversos individuos de uma mesma coletividade. Neste último caso, buscase uma convergência de relatos sobre um mesmo acontecimento ou sobre um periodo de tempo. A História oral pode captar a experiência efetiva dos narradores, mas também recolhe destas tradiçoes, mitos, narrativas de ficção, crenças existentes no grupo" (Pereira de Queiroz, 1988:19).

"É constituida por um conjunto sistemático, diversificado e articulado de depoimentos gravados em torno de um tema" (Camargo, 1988:VII).

\section{2 - História de Vida}

Enquanto "espécie" dentro do amplo quadro de História Oral, para Pereira de Queiroz a História de Vida: 
"(..) se define como o relato de um narrador sobre sua existência através do tempo, tentando reconstituir os acontecimentos que vivenciou e transmitir a experiência que adquiriu. Narrativa linear e individual dos acontecimentos que nele considera significativos, através dela se delineiam as relações com os membros de seu grupo, de sua sociedade global, que cabe ao pesquisador desvendar. Desta forma, o interesse deste último está em captar algo que ultrapassa o caráter individual do que é transmitido e que se insere nas coletividades a que o narrador pertence. (...) Este (o entrevistado) é quem determina o que é relevante ou não narrar, ele é quem detém o fio condutor" (Pereira de Queiroz, 1988:20-1).

" (...) tem como centro de interesse o próprio indivíduo na História, incluindo sua trajetória desde a infância até o momento em que fala, passando pelos diversos acontecimentos e conjunturas que presenciou, vivenciou ou inteirou" (Alberti, 1989:18-19). (Considera-se) "sempre as estruturas sociais $e$ os momentos bistóricos nos quais se inseriu a trajetória do sujeito dentro da bistória" (Alberti, 1989:68).

\section{3 - Depoimento Pessoal}

“(..) se constituem em um relato da experiência individual que revele as ações do indivíduo como agente bumano e como um participante da vida social (...). Através desta técnica, segundo Aracy Nogueira, procura-se descobrir a concepção que o indivíduo tem de si mesmo, como a que os demais têm dele" (Kosminsky, 1986:32).

"(...) difere da bistória de vida na forma especifica de agir do pesquisador, o qual, no depoimento pessoal, dirige diretamente o colóquio" (Pereira de Queiroz, 1986:32).
"Concentrado sobre um lapso de tempo mais reduzido, permite aprofundar o numero de informações $e$ de detalhes a respeito desse espaço preciso" (Pereira de Queiroz, 1983:147-8).

\section{4 - Autobiografia}

"É o narrador sozinbo que manipula os meios de registro, quer seja a escrita, quer o gravador. Foi ele também que, por motivos estritamente pessoais, resolveu narrar sua existência; deu-lhes o encaminhamento que melhor lhe pareceu" (Pereira de Queiroz, 1988:23).

\section{5 - Biografia}

"É a bistória de um indivíduo redigida por outro. Existe aqui a dupla intermediação que a aproxima da bistória de vida, consubstanciada na presença do pesquisador e no relato escrito que sucede às entrevistas. $O$ objetivo do pesquisador é desvendar a vida particular daquele que está entrevistando, mesmo que neste estudo atinja a sociedade em que vive o biografado, o intuito é, através dela, explicar os comportamentos e as fases da existência individual. A finalidade é sempre um personagem" (Pereira de Queiroz, 1988:23).

A análise dos conceitos e defınições apresentados permite sintetizar alguns aspectos:

- O ponto de partida para o pesquisador buscar respostas às questôes que formulou é a fala dos sujeitos, como de resto se dá em outras técnicas qualitativas. Entretanto, no conjunto de instrumentos denominados Relatos Orais, esta fala gira em torno da experiência de vida dos indivíduos. Esta experiência pode ser recortada de maneiras distintas, demarcando as diferenças entre as diversas técnicas; 
- Na História Oral, o recorte se dá na coleta e registro de relatos sobre fatos, acontecimentos ou mesmo períodos históricos testemunhados pelo entrevistado, cujo conhecimento se deseja ampliar ou completar;

- Já nas Histórias de Vida, o eixo do relato situa-se na reconstrução da trajetória de vida do indivíduo descle a infância até a atualidade. Mas, nelas, o objetivo do pesquisador não é descrever um personagem - como seria na Biografia, e sim ultrapassar o caráter individual e singular do que the é transmitido, rumo ao desvelamento das relações sociais nas quais se insere.

A técnica de Depoimentos Pessoais, por seu turno, concentra o relato na história do entrevistado focalizada sob um prisma de interesse definido pelo pesquisador. Nela, diferentemente da História de Vida, este tem um papel ativo na direção da narração, procurando aprofundar o conhecimento sobre o recorte que elegeu, mantendo entretanto a preocupação de superar a dimensão individual do relato e encontrar nele o coletivo.

\section{III - Pressupostos}

A validação das técnicas qualitativas de pesquisa, em seu conjunto, tem sido marcada por reflexões e debates de seus pressupostos, seja em relação às técnicas quantitativas - que necessariamente "não são opostas e inconciliáveis" (Cardoso, 1986:96), seja em relação à própria crítica teórico-metodológica que deve acompanhar, de forma consistente, o seu desenvolvimento.

Delineando sua crítica ao empiricismo pela ausência de problematização do real "fotografado" e pelo não reconhecimento da mediação de categorias em sua apreensão pelo investigador -, Thiollent destaca, apoiado por outros autores neste debate, dois pressupostos de repercussões profundas na concepção metodológica:
- A objetividade como mito: no lugar da crença no real absoluto, passivel de ser apreendido de forma objetiva, considera-se que "jamais poderemos apreender o real tal como ele é; apesar disso insistimos em obter uma aproximação cada vez mais acurada dele, para aumentar qualitativa e também quantitativamente o nosso conbecimento" (Alberti, 1989:6). Ou, no dizer de Thiollent: "A objetividade é relativa, na medida em que o conhecimento social sempre consiste em aproximaçôes sucessivas relacionadas com perspectivas de manutenção ou de transformação" (Thiollent, 1987:28);

- A neutralidade científica como mito: a idéia da objetividade supõe a existência de um sujeito cognoscente neutro, capaz de partir do fato bruto, observado sem a mediação de categorias ou de um quadro teórico preexistente. Referindo à "ilusão da imaculada percepção", o mesmo autor afirma que "a neutralidade é falsa ou inexiste, na medida em que qualquer procedimento de investigaçâo envolve pressupostos teóricos e práticos variáveis segundo os interesses sócio-politicos que estão em jogo no ato de conbecer" (Thiollent, 1987:28).

No tocante especificamente aos Relatos Orais, a bibliografia consultada apresenta os seguintes pressupostos:

- "(...) todos os seres bumanos compreendem uma humanidade básica, isto é, a identidade da natureza bumana persiste, apesar das diferenças e características pessoais" (Young, apud Kosminsky, 1986:32);

- "(...) o individuo é sempre membro de um grupo cultural ou comunidade, e seu comportamento é uma resposta a estímulos sociais definidos" (Dollard, apud Kosminsky, 1986:33);

- "Através do estudo da vida dos individuos, é possivel conbecer caracteristicas, valores, estruturas da sociedade na qual está inserido" (Pereira de Queiroz, 1986:28). 
Estes pressupostos, entretanto, geram polêmicas desde os trabalhos pioneiros de $\mathrm{J}$. Dollard, Thomas e Znaniecki: como a história de vida de um indivíduo, ou o seu relato sobre fatos que testemunhou, pode interessar às Ciências Sociais? Como uma narração carregada de subjetivismo pode ser tratada como fonte de informação e, mais que isto, como técnica ou método de investigação?

Tal polêmica, centrada na subjetividade como fator de erro/desvio ou de enriquecimento/ampliação do conhecimento social, parece ser reflexo, no campo metodológico -, face à necessidade de articulação entre teoria e método - do debate teórico acerca da relação indivíduo-sociedade. Apesar de sua complexidade, registram-se a seguir alguns pontos deste debate, pela importância que têm na discussão dos pressupostos.

Augusto dos Santos Silva recupera, no plano epistemológico, a caminhada desta reflexão a partir do século XIX, quando a burguesia liberal adotou o individualismo (e o utilitarismo) como matriz ideológica para a implantação de seu sistema econômico e político, difundindo "a idéia de que a sociedade é um agregado de individuos singulares e de que a prossecução dos seus interesses por parte de cada um deles serve de melhor garantia para a harmonia coletiva" (Silva, 1987:39).

Este postulado contamina as teorias científicas até o nascimento da Sociologia - quando parece ir ao extremo oposto:

"(...) da tradição durkbeimiana ao estruturalismo se tem procurado resolver o problema (da relação entre indivíduos e sociedade) pela evacuação do ator do objeto da análise, ator quase reduzido a mera conseqüência de determinismos sociais que escapam à sua consciência (Silva, 1987:40).

“(...) A ênfase, nesta linha, é colocada na morfologia social, na uniformidade, na regularidade" (Van Velsen, 1987:354).
No entanto, Eder Sader afirma com força que os consagrados esquemas explicativos dos processos sociais que os relacionam às características estruturais não adicionam "uma virgula à compreensão do fenômeno" (Sader, 1988:38). Também Ruth Cardoso aponta a insuficiência desta perspectiva: por que não se encontrava a "revolta esperada"? E fala das tentativas de "desvendar as teias que ligam os macroprocessos econômicos e os comportamentos concretos" (Cardoso, 1986:96-7). Por que, diante de situações estruturais de miséria e opressão, as pessoas e os grupos reagem num leque matizado entre a submissão e a revolta? (Moore Jr., 1987:13). Como "as classes populares" brasileiras, indubitavelmente "subsumidas pela lógica do capital e do seu Estado", despontam com força no cenário político dos anos 70? (Sader, 1988:2535).

Emerge então, na trajetória das Ciências Sociais, a noção de sujeito, e com ele a atenção para a cultura, o imaginário, o simbólico. Surge o interesse em conhecer como, a partir de condições históricas e estruturais particulares e das experiências vivenciadas coletivamente, os indivíduos constroem representações de si e da realidade que os cerca, articulando, num sistema simbólico, valores, necessidades e desejos que nortearão sua ação no mundo.

Parece ser neste contexto de emersão do sujeito e da cultura - como elementos de peso na nova apreciação da relação indivíduo-sociedade - que situa-se hoje a discussão dos pressupostos dos relatos orais. A posição de Augusto dos Santos Silva é que:

“ (...) individuos e sociedade não são realidades separáveis (a não ser, decerto, logicamente) de tal modo que se pudesse estudar um dos termos evacuando o outro - abordar o individuo independentemente do supra-individual (tentação do psicologismo) ou a sociedade omitindo a ação intencional dos sujeitos (risco do sociologismo)" (Silva, 1987:41). 
Maria Isaura P. Queiroz também posiciona-se sobre esta questão:

"Todo fenômeno social é total, dizia Marcel Mauss nas décadas de 20. O individuo é também um fenômeno social. Aspectos importantes de sua sociedade e de seu grupo, comportamentos e técnicas, valores e ideologias podem ser apanbados através de sua história" (Pereira de Queiroz, 1988:28).

Esta autora defende que a vida do indivíduo assenta-se sobre duas perspectivas sua herança biológica, com suas peculiaridades; e sua sociedade, com sua organização e valores específicos - os quais, interagindo, desenham sua personalidade. Daí adviria a validação das histórias de vida como objeto das Ciências Sociais. Para sustentar que o subjetivismo não decorre exclusivamente de bases biológicas e psicológicas, recorre a duas linhas de pensamento. A primeira defende que as funções vegetativas - necessidades físicas, inclinações, prazer e dor - geram sensações que, ao serem percebidas pelos indivíduos, passam pela mediação do que lhes é exterior, definido socialmente (Pereira de Queiroz, 1988:38). A Antropologia tem recolhido inúmeros exemplos de como a fome, o parto, os dejetos humanos, a doença, a morte, são tratados de forma diferente em cada cultura (Rodrigues, 1983). A segunda linha de pensamento baseia-se em Jung, para quem a existência de algumas representações simbólicas arquetípicas, comuns a todos os indivíduos através dos tempos e raças, sugere a semelhança das estruturas mentais sobre as quais repousam o "inconsciente coletivo", demonstrando o caráter social do psiquismo.

Esta breve retomada nos permite dizer que a compreensão dos fenômenos sociais tende agora a não mais concentrar suas explicações no pólo do indivíduo, nem no pólo das estruturas sociais. O desafio é romper com a idéia da sociedade enquanto aglomerado de indivíduos ou, ao contrário, do co- letivo social como algo que paira desencarnado sobre os indivíduos, determinando-os de maneira totipotente; compreender a dialética do homem como produto social, mas também produtor da sociedade; o desafio é exatamente situar-se na tensão sujeito-estrutura, indivíduo-sociedade.

Parece que isto não tem sido fácil, nem do ponto de vista teórico, nem do ponto de vista metodológico. Maria Isaura P. Queiroz, por exemplo, embora argumente a favor da recuperação da subjetividade nas pesquisas sociais e defenda as técnicas de relato oral por "captarem o que sucede na encruzilhada da vida individual com o social" (Pereira de Queiroz, 1988:35), afirma com ênfase que:

"o sociólogo vai na direção do que é coletivo, geral, não se detendo nos particularismos (...). Não se trata de considerá-lo (o individuo) isoladamente, nem de compreendêlo em sua unicidade; o que se quer é captar, através de seus comportamentos, o que se passa no interior das coletividades de que participa. O indivíduo não é mais o 'único'; ele agora é uma pessoa indeterminada, que nem mesmo é necessário nomear, é somente unidade dentro da coletividade" (Pereira de Queiroz, 1988:24-5).

O tom destas linhas sugere que, para distanciar-se do "risco do psicologismo", podemos cair na "tentação do sociologismo", ou vice-versa (Silva, 1987:41).

Apesar disto, permanece toda a potencialidade da técnica, bem expressa por Aspásia Camargo ao avaliar a experiência do CPDOC:

"Foi possivel também, de certa forma, romper o enclausuramento acadêmico que transformava a entrevista em simples suporte documental - e duvidoso - da pesquisa social e histórica, para mostrar a riqueza inesgotável do depoimento oral em si mesmo, como fonte não apenas informativa, mas, sobretudo, como 
instrumento de compreensão mais ampla $e$ globalizante do significado da ação bumana; de suas relações com a sociedade organizada, com as redes de sociabilidade, com o poder e o contrapoder existentes, e com os processos macroculturais que constituem o ambiente dentro do qual se movem os atores $e$ os personagens deste grande drama ininterrupto - sempre mal decifrado - que é a História Humana" (Camargo, 1989:VIII).

Nesta perspectiva, o que é visto por Guitta Debert como "decepcionante" - os Relatos Orais estão sempre convidando a discutir conceitos tidos como definitivos, a rever interpretações, a desenvolver novas hipóteses (Debert, 1986:150-6) - pode ser visto como vantagem. Esta problemática terá reflexos na discussão da adequação destas técnicas ao estudo das representações sociais em saúde, discutida no item IV.

\section{IV - Discutindo a Adequação das Técnicas de Relatos Orais ao Estudo das Representações Sociais em Saúde}

Além de dominar as técnicas de pesquisa, é necessário avaliar com rigor a adequação entre o objeto de estudo - e o marco teórico que o recorta - e a metodologia a ser adotada na pesquisa. Neste item faremos esta discussão, tomando, como exemplo aplicativo, um estudo das representações sociais sobre corpo e trabalho presentes no imaginário de trabalhadores.

\section{IV.1 - Recortando \\ as Representações Sociais como Objeto de Estudo}

O interesse em estudar e compreender as representações sociais sobre corpo e trabalho entre trabalhadores, que embasam seu discurso e ação no tocante à saúde, surge de um sentimento de indignação, enquanto profissional e ser humano, diante das precárias condições de saúde da maioria da população brasileira e de uma convivência cotidiana, no Ambulatório de Doenças Profissionais da UFMG, com a violência do impacto do trabalho sobre a saúde dos trabalhadores. Entretanto, um mínimo de conhecimento das Ciências Sociais permite elaborar uma explicação teórica para esta realidade, que passa pela organização da sociedade em função dos interesses da produção e do lucro, pela divisão internacional do trabalho (e dos riscos), etc. Mas a indignação e as perguntas persistem: por que os trabalhadores aceitam isto? $\mathrm{Ou}$, ao contrário, como outros trabalhadores reagem contra isto?

Percebo que, se por um lado, já foram construídas explicações "estruturais" para o problema, por outro, pouco se conhece ainda sobre como os trabalhadores vêem esta questão. As respostas tradicionais - "agüentam porque precisam do trabalho para sobreviver"; "aceitam porque ignoram os riscos e conseqüências" - parecem-me, no mínimo, incompletas e insuficientes, já que não abrem perspectivas e deixam o futuro nas mãos do avanço autônomo da economia e do "progresso".

Se...

"os fatos humanos são sempre fatos interpretados, e se a consciência dos atores é o elemento constitutivo decisivo do mundo social, importa dar conta das representações coletivas, cotidianas, da sociedade - as imagens $e$ as noções construidas no decurso da vida de todos os dias e que configuram o patrimônio cognitivo partilhado pelos membros de um dado grupo, as maneiras de pensar e de sentir" (Silva, 1987:31, grifo meu).

A apreensão do mundo pelos sujeitos não se dá como projeção direta, em suas cons- 
ciências, do real. Ela é mediada pela sua capacidade de inventar, de criar, de evocar imagens e símbolos, de atribuir significados, de re-apresentar (Moscovici, 1979). São as representações sociais: imagens e noções construídas no decurso da vida cotidiana e que configuram o patrimônio cognitivo, as maneiras de pensar e de sentir partilhados pelos membros de um grupo (Silva, 1987:31).

É, portanto, no terreno das representações sociais que pretendo encontrar pistas para a compreensão das posturas dos trabalhadores diante de sua saúde (ou não-saúde). A experiência pregressa indica-me que estas posturas são diversas: transitam num leque que vai desde a negação do problema até a assunção de si enquanto sujeito no processo coletivo de transformação da realidade. Vejo também que seu discurso e ação são dinâmicos, alteram-se ao longo da existência de um mesmo indivíduo.

Parto, então, das seguintes perguntas:

Como trabalhadores representam o corpo e sua relação com o trabalho?

Como estas representações são construídas?

Em que condições elas se modificam?

No processo de construção das representaçôes sociais, parece ter papel importante a ideologia vigente, já que as idéias dominantes numa sociedade deixam seus traços em todos os homens e mulheres que nela se fazem e se vêem (Jodelet, 1987).

Entretanto, embora sejam o locus de atualização da ideologia, as representações sociais não se reduzem a ela. A percepção do objeto é marcada também pela história vivida do sujeito e pela forma como ele se insere no sistema social (Abric, 1987). As representações sociais não são, portanto, meros espaços de reprodução do instituído, pois carregam consigo as marcas do potencial de negação presente em cada ser humano, dos con- flitos e contradições deste social que elas articulam. Num mesmo indivíduo podem conviver representações singulares a ele, particulares ao seu grupo social e gerais à sociedade onde vive, não necessariamente articuladas e coerentes. Este caráter dinâmico e ambíguo das representações vai refletir-se no processo de construção da identidade dos sujeitos, transformando-a em resposta a mudanças tecnológicas, políticas e culturais (Erikson, 1974:586-591). São, por isto, conjuntos dinâmicos, onde há um espaço possível de autonomia, ainda que na heteronomia.

Desta forma, pode-se compreender, em primeiro lugar, que os trabalhadores introjetem elementos da visão hegemônica sobre a relação entre a saúde e o trabalho. Esta introjeção é necessária para sustentar e justificar sua adesão ao contrato social em que se inscrevem, e os faz "agüentar" seu cotidiano numa atitude aparentemente passiva:

"Trabalhar é inserir-se no tecido social, por mediação de uma práxis, aceitando a ordem simbólica que o constitui. $\hat{E}$ disciplinar-se, é abrir mão da arrogância e da onipotência primitivas e assumir os valores da cultura com a qual, através do trabalbo, nos articulamos organicamente" (Pellegrino, 1983:5)

Neste processo de "socialização" está contida a introjeção de fórmulas culturais que definem as necessidades socialmente aceitáveis, o significado e as causas do sofrimento humano e o que o indivíduo pode ou deve fazer contra ele. Estas fórmulas desenham o âmbito de respostas possíveis aos sujeitos. Sua adoção, segundo Moore Jr., é facilitada por processos sociais que envolvam a destruição de hábitos e vínculos grupais anteriores, a cooptação e a fragmentação, os quais criam o sentido de que a dor e o sofrimento são acompanhados de "autoridade moral" (1987:81-121). Por isso, introjetam também a representação de saúde como a "disposição 
para trabalhar", conforme a cultura hegemônica tenta impor aos setores subalternos da sociedade, centrando a produção simbólica nas relações econômicas (Sahlins, 1979:236) e reduzindo o corpo do trabalhador e sua saúde a meros instrumentos-mercadoria (Boltanski, 1984; Canesqui \& Queiroz, s.d.; Deleule \& Guery, 1975; Dejours, 1987; Muraro, 1983). É possível, assim, compreender por que a reação dos trabalhadores às condições nocivas de trabalho, à mutilação de seus corpos, ao sofrimento e à dor não é imediata nem linear.

Mas Freud traz elementos para a compreensão de outra face deste movimento:

"No processo de desenvolvimento do individuo o programa do princípio do prazer, que consiste em encontrar a satisfação da felicidade, é mantido como objetivo principal" (Freud, 1976:164).

O cotidiano do trabalho, embora possa trazer gratificações e retornos positivos aos trabalhadores, também expõe e atualiza as fissuras e contradições da cultura hegemônica sobre a relação entre a saúde e o trabalho, ao negar desejos e expectativas desenhados pela pulsão de vida. Eles podem ver as transformações de seus corpos e de seus colegas. As doenças e os acidentes do trabalho podem ser momentos agudos de desvelamento destas contradições, nos quais se reinterpreta coletivamente o discurso da sociedade, cumprindo, assim, o papel de sinal (Berlinguer, 1988:94-117).

Deste conflito entre os desejos do sujeito e o real por ele vivido surge o questionamento do código cultural vigente e do contrato social que o consolida. E,

"(...) com toda justiça, consideramos fatho o presente estado de nossa civilização, por atender de forma tão inadequada às nossas exigências de um plano de vida que nos torne felizes, e por permitir a existência de tanto sofrimento, que provavelmente poderia ser evitado" (Freud, 1976:138).

A angústia gestada neste processo de questionamento da estabilidade e coerência da sociedade na qual se insere, pode derivar, ao nível dos sujeitos, num abafamento dos conflitos ou, em algumas condições históricas concretas, na busca de agenciar e atualizar fórmulas culturais autônomas. A forma pela qual as pessoas definem o valor daquilo com que contribuem para uma relação social - seu investimento - e daquilo que dela extraem - sua recompensa - vai se modificando (Moore Jr., 1987:79). Neste processo, até mesmo a doença pode passar a ser estímulo à contestação e à definição de novos interesses.

E, se a cultura não está fora da realidade material, mas é parte dela, criada e mantida pelo comportamento dos grupos humanos, é também objeto e lugar de disputa dos conflitos sociais: novas representações sociais, construídas a partir da vivência cotidiana das contradições e de sua elaboração pelos sujeitos sociais, conformam novas identidades, ordenam novos comportamentos e gestam novo contrato social (Rigotto, 1992:46).

\section{IV.2 - Casando Objeto- Metodologia...}

Dentro desta construção teórica sobre as representações sociais, onde estão contidas as hipóteses do estudo, a perspectiva de adotar o Relato Oral ganha consistência. Dentre suas técnicas, a de depoimento pessoal, cruzando a biografia dos entrevistados com o tema corpo e trabalho, parece adequada.

Os sujeitos a serem entrevistados seriam escolhidos entre trabalhadores que conheço profissionalmente (como pacientes, dirigentes sindicais etc.), e que apresentem, aos meus olhos, posturas diversas em relação à saúde 
- classificadas, num primeiro momento, como tipos-ideais:

- O desenvolvimento de estratégias defensivas "eficazes" de negação da existência ou da gravidade do problema;

- O desenvolvimento de estratégias defensivas de negação, com conflito intrapsíquico;

- O desenvolvimento de estratégias individuais de resistência à expropriação da saúde;

- O desenvolvimento de estratégias coletivas de resistência à expropriação da saúde;

A "vigilância epistemológica" aconselhada por Bourdieu permitiria, durante a coleta dos depoimentos pessoais, questionar a adequação do leque de tipos-ideais, da classificação do indivíduo em um deles e, acredito, verificar a dinamicidade destas posturas, a rigor classificáveis apenas num flash lógico, mas na realidade profundamente imbricadas.

A interpretação dos dados seria feita através da análise de conteúdo:

" (...) um conjunto de técnicas de análise das comunicações visando obter, por procedimentos sistemáticos e objetivos de descrição de conteúdos das mensagens, indicadores (quantitativos ou não) que permitam a inferência de conbecimentos relativos às condições de produção/recepção (variâveis inferidas) destas mensagens" (Bardin, 1979:42).

A partir dela poderia inferir resultados que nos aproximariam do conhecimento das representações sociais sobre corpo e trabalho e seu processo de construção/transformação.

\section{IV.3 - ...por suas Compatibilidades...}

Em que medida estes pressupostos teórico-metodológicos, construídos através da vivência, do estudo e da reflexão não-neu- tras, são compatíveis com os que embasam os Depoimentos Pessoais?

Em primeiro lugar, pelo próprio processo de construção do objeto de estudo, nascido de um interesse profundo em compreender o processo através do qual os indivíduos agem desta ou daquela forma em relação à sua saúde, ou seja, o processo de construção do sujeito no tocante à saúde. Processo, porque parece que a explicação de idéias/ condutas do indivíduo pode ser encontrada ao longo de sua história, numa trama que vai tecendo de forma singular entre o que ouviu, viu, pensou, sentiu, acreditou, temeu: sua vida. As técnicas de relatos orais, como um todo, colocam o sujeito num lugar de destaque, valorizando as experiências que viveu e o que tem a dizer sobre elas. Pelas suas características, tanto a história de vida como os depoimentos pessoais e a biografia dariam acesso a este tipo de informação.

Em segundo lugar, as representações sobre corpo, saúde e trabalho - assim como outras - enquanto conjunto complexo de significados, são marcadas pelo tempo e espaço histórico dos grupos humanos. Sua produção dá-se exatamente na interseção entre a singularidade do indivíduo e a cultura onde ele se insere. É possível - e desafiante - visualizar, nas histórias de vida e depoimentos pessoais, o espaço bifacetário e tenso indivíduo-sociedade.

Como terceiro ponto de compatibilidade, há o interesse em conhecer não só as formas particulares como os indivíduos constroem suas representações sobre corpo e trabalho, mas também de poder aproximar, ainda que minimamente, de uma ampliação ao que poderia ser chamado "cultura sobre corpo e trabalho" num segmento social. Se este é o olhar do pesquisador, estas técnicas permitem conhecer, através das falas dos sujeitos, os valores, crenças, padrões que constituem esta cultura e são por eles apropriados.

Um quarto aspecto seria o próprio caráter de transição, de "estar entre", de duas 
categorias centrais no estudo proposto. De um lado, a categoria corpo, entre o biológico e o social, entre a natureza e a cultura. De outro, a categoria representação, entre o psíquico e o social, entre a idéia e a ação, entre produto e produtora da cultura.

Finalmente, aponto a relativa facilidade de execução da técnica (ver Anexo), se comparada, por exemplo, à observação etnográfica. Este fator pesa também na definição pelos Depoimentos Pessoais, em detrimento das Histórias de Vida, cujas aplicações são muito semelhantes. É que aqueles, além de demandarem um tempo menor de trabalho de campo (duração e número de entrevistas, sua transcrição e análise), supõem um direcionamento na condução dos relatos. Isto pode permitir um aprofundamento maior das questões que tenho e facilitar a ordenação do trabalho (para não ficar, como Guitta Debert, decepcionada "diante de um monte de fragmentos desconexos, incoerentes e ambíguos") (Debert, 1986:150).

\section{IV.4 - ... embora possa prever Dificuldades}

Neste momento, é possível prever algumas dificuldades, que talvez possam ser contornadas.

A primeira delas é o fato de, como pesquisadora, ter um conhecimento prévio das pessoas que deverão ser entrevistadas. É necessário considerar "a natureza intersubjetiva da relação entre o pesquisador e seu informante" (Cardoso, 1986:103). Certamente os entrevistados já possuem alguma imagem sobre a pesquisadora, construída a partir dos contatos anteriores. Esta imagem, que provavelmente é diferente entre eles (minha médica, professora universitária, participante da Escola Sindical etc.), influirá no que eles terão a dizer na entrevista. Ouvindo Thiollent, será necessário realizar uma sociologia da situação de entrevista, para avaliar e contro- lar, se possível, as distorções disto oriundas.

A segunda é menos uma dificuldade e mais um "incômodo". É marcante, a partir do contato com a teoria e a metodologia antropológicas, a importância de não ter como base para o trabalho empírico apenas o discurso dos atores, mas também a ação que desenvolvem. Porque "uma pessoa que responde a um questionário nada mais faz do que escolher uma categoria de respostas; ela transmite-nos uma mensagem particular. Transmitenos seu desejo de ver as coisas evoluirem num sentido ou noutro" (Moscovici, 1979:49, grifo meu). Talvez este risco seja um pouco reduzido nos Depoimentos Pessoais, que não se limitam à emissão de opiniões sobre questões levantadas pelo pesquisador, mas estimulam o entrevistado a falar de como pensou e como fez. Outra possibilidade é a complementação com dados de outras fontes, sugerida desde Thomas e Znaniecki: os próprios prontuários médicos (por exemplo, documento de alta de tratamento sob responsabilidade), documentos dos sindicatos etc.

\section{V - Considerações Finais}

É crescente, entre os pesquisadores no campo da Saúde Coletiva, o interesse em estudar as representações sociais, nos mais variados recortes. Percebe-se a importância de conhecer os sistemas simbólicos que articulam os valores, necessidades, desejos, e que norteiam a ação dos indivíduos e grupos sociais em relação ao corpo e à saúde, para compreender comportamentos, orientar serviços e ações, elaborar políticas, mobilizar e organizar.

As técnicas de Relatos Orais, em seu conjunto, colocam o sujeito e sua cultura em lugar de destaque: partem de sua fala, centrada na experiência própria de vida, mas postulando que a história dos indivíduos contém e registra comportamentos, técnicas, valores e ideologias de seu grupo e de sua 
sociedade. Permitem, assim, desvendar, na cultura, as teias que ligam os macroprocessos econômico-sociais e as pessoas, captando o que sucede na encruzilhada indivíduo-sociedade, sujeito-estrutura.

Desta forma, a História Oral, a História de Vida, o Depoimento Pessoal, a Autobio- grafia e a Biografia são ferramentas úteis para os pesquisadores na área de saúde, que podem auxiliar no processo permanente de buscar compreender, a partir das representações sociais, esta complexa rede da história e da cultura humanas, onde o processo saúde-doença vai sendo desenhado.

\section{Anexo}

\section{Aspectos da Execução da Pesquisa Empírica com as Técnicas de Relatos Orais}

Aspectos a serem considerados no planejamento/execução da pesquisa empírica com as técnicas de Relatos Orais, de acordo com a experiência do CERU (von Simon, 1988) e do CPDOC (Alberti, 1989).

\section{1 - Procedimentos Iniciais}

Estudo exaustivo do tema da investigação.

Escolha do tipo de entrevista, conforme sua adequação aos objetivos da pesquisa: História de Vida, Depoimento Pessoal, Biografia.

Preparação do roteiro geral de entrevistas, contendo todos os tópicos a serem considerados em cada relato.

Preparação de roteiro individual de entrevistas, conforme a biografia de cada entrevistado.

Preparação do equipamento de gravação: verificar contatos elétricos, voltagem, cabeçote, volume, pilhas, aderências nas fitas etc.

Contato inicial com o entrevistado, tornando clara a relevância de sua contribuição e o respeito do pesquisador pela sua experiência. Descrever francamente os propósitos da Pesquisa e informar sobre o uso que será feito de seu relato.

Preparar o caderno de campo, onde deverão constar observações sobre o entrevistado, a relação com ele desde o contato inicial, canais de mediação, e, posteriormente, reações à entrevista, descrição detalhada da situação de entrevista, impressões sobre o grau de liberdade de expressão, informaçōes fornecidas com o gravador desligado, etc. Este será um instrumento de crítica e avaliação do alcance e limitação da pesquisa.

\section{2 - A Realização da Entrevista}

Local: estabelecido de comum acordo entre pesquisador e entrevistado, com condições de conforto suficientes para não perturbar a coleta do depoimento.

Duração: é aconselhável não exceder a duas horas, marcando novo encontro, se necessário.

Apresentação do pesquisador de forma a não chamar a atençâo do entrevistado, conforme sua situaçâo social. Tentar evitar a presença de terceiros.

Sobre a relação de entrevista: considerar que sujeitos distintos, com visões de mundo, experiências, linguagem, saber, idades diferentes, estào se encontrando em torno de um tema. Cabe ao pesquisador exatamente conhecer essa alteridade, respeitando-a, inclusive em seu ritmo, na forma cle articular o pensamento. Como qualquer outra relação humana, ela parte de um estranhamento inicial e progride, idealmente rumo à empatia.

Preparação de roteiro parcial de entrevista, com base no roteiro individual, entre uma sessão e outra.

\section{3 - Procedimentos Posteriores}

Rebobinamento, identificação e duplicaçào das fitas de gravação.

Transcrição: idealmente feita pelo próprio pesquisador, deve registrar ênfases, silêncios, risos, emoções; corrigir palavras contraídas (né, tá, etc.).

Conferência de fidelidade: acrescentar descrição de circunstâncias e gestos, anotados no caderno de campo, necessários para a compreensão do texto. Conferir siglas e nomes próprios.

Leitura final, digitação e revisão. 


\section{Referências bibliogrâficas}

ABRIC, J.C. (1987) - L'Étude Expérimentale des Represéntations Sociales. In: Jodelet, D. (org.) Représentations Sociales: Un Domaine en Expansion. Paris: PUF.

ALBERTI, V. (1989) - História Oral: A Experiência do CPDOC. Rio de Janeiro: Centro de Pesquisa e Documentaçâo de História Contemporânea do Brasil

BARDIN, L. (1979) - Análise de Conteúdo. Lisboa: Ediçôes 70.

Berlinguer, G. (1988) - A Doença. São Paulo: Hucitec

BOLTANSKI, L. (1984) - As Classes Sociais e o Corpo. 2. ${ }^{\text {a }}$ ed. Rio de Janeiro: Graal.

CAMARGO, A. (1989) - Apresentação. In: Alberti, V. - História Oral: A Experiencia do CPDOC. Rio de Janeiro: Centro de Pesquisa e Documentação de História Contemporânea do Brasil.

CANESQUI, A. \& QUEIROZ, M.C. (s.d.) - Famílias Trabalhadoras e Representações sobre Saúde, Doença e Aspectos Institucionais da Medicina "Oficial" e "Popular". Núcleo de Estudos de Políticas públicas. Cadernos de Pesquisa 7. Campinas: UNICAMP.

CARDOSO, R.C.L. (1986) - Aventuras de Antropólogos em Campo ou como Escapar das Armadithas do Método. In: Cardoso, R.C.L. (org.) $-A$ Aventura Antropológica. Rio de Janeiro: Paz e Terra.

DEBERT, G.G. (1986) - Problemas Relativos à Utilização da História de Vida e História Oral. In: Cardoso, R.C.L. (org.) - A Aventura Antropológica. Rio de Janeiro: Paz e Terra.

DEJOURS, C. (1987) - A Loucura do Trabalbo. São Paulo: Oboré.

DELEULE, D. \& GUERY, F. (1975) - El Cuerpo Productivo: Teoria del Cuerpo en el Modo de Producción Capitalista. Buenos Aires: Tiempo Contemporáneo.

DURKHEIM, E. (1974) - As Formas Elementares da Vida Religiosa. In: Os Pensadores. São Paulo: Abril Cultural, vol. XXXIII.

ERIKSON, E. (1974) - Verbete "Identidade Psicossocial". In: Sillis, D.L. (Dir.) - Enciclopedia
Internacional de Ciencias Sociales. Madri: Aguilar

FREUD, S. (1976[1929]) - O Mal Estar na Civilização. In: -. Obras Completas. Rio de Janeiro: Imago Editora.

JODELET, D. (org.) (1987) - Représentations Sociales: Un Domaine en Expansion. Paris: PUF.

KOSMINSKY, E. (1986) - Pesquisas Qualitativas: A Utilizaçào da Técnica de Histórias de Vida e de Depoimentos Pessoais em Sociologia. Ciência e Cultura 38(1):30-36.

MOORE JR., B. (1984) - Injustiça, as Bases Sociais da Obediência e da Revolta. São Paulo: Brasiliense.

MOSCOVICI, S. (1979) - A Representação Social da Psicanálise. Rio de Janeiro: Jorge Zahar Editor.

MURARO, R.M. (1983) - Sexualidade da Mulher Brasileira: Corpo e Classe Social no Brasil. Petrópolis: Vozes

PELLEGRINO, H. (1983) - "Pacto Edípico e Pacto Social". Pronunciamento feito no Teatro Ruth Escobar, em 8 de julho de 1983, num debate sobre a peça Édipo-Rei, de Sófocles, São Paulo, mimeo

PEREIRA DE QUEIROZ, M.I. (1988) - Relatos Orais: Do Indizível ao Dizível. In: von Simon, O.M. (org.) - Experimentos com História de Vida (Itália-Brasil). São Paulo: Vértice.

PEREIRA DE QUEIROZ, M.I. (1983) - Variações sobre a Técnica de Gravador no Registro da Informação Viva. Coleção Textos 4. São Paulo: CERU e FFLCH/USP.

RIGOTTO, R. (1992) - "Não Somos Máquinas": Um Estudo das Ações Sindicais em Defesa da Saúde do Trabalhador na Grande BH. Dissertação de Mestrado. Faculdade de Educaçâo da Universidade Federal de Minas Gerais, Belo Horizonte, mimeo.

RODRIGUES, J.C. (1983) - O Tabu do Corpo. 3." ed. Rio de Janeiro: Achiamé.

SADER, E. (1988) - Quando Novos Personagens entraram em Cena. Rio de Janeiro: Paz e Terra. SAHLINS, M. (1979) - A Utilidade e a Ordem Cultural. In: Sahlins, M. - Cultura e Razão Prática. 
Rio de Janeiro: Jorge Zahar Editor.

SILVA, A.S. (1987) - A Ruptura com o Senso Comum nas Ciências Sociais. In: Silva, A.S. \& Pinto, J.M. (orgs.) - Metodologia das Ciências Sociais. Porto: Apontamento.

THIOLLENT, M.J.M. (1987) - Crítica Metodológica Investigação Social e Enquete Operária. 5.. ed. São Paulo: Pólis.
VAN VELSEN, J. (1987) - A Análise Situacional e o Método de Estudo de Caso Detalhado. In: Feldman-Bianco, B. (org.) - Antropologia das Sociedades Contemporâneas - Métodos. São Paulo: Global.

VON SIMON, O.M. (Org.) (1988) - Experimentos com História de Vida (Itália-Brasil). São Paulo: Vértice. 